\title{
Molecular characterization of Brucella ovis in Argentina
}

\author{
Lucía P. Alvarez $^{\mathrm{a}, *}$, Nazaret Ruiz-Villalobos ${ }^{\mathrm{b}}$, Marcela Suárez-Esquivel ${ }^{\mathrm{b}}$, Nicholas R. Thomson ${ }^{\mathrm{c}}$, \\ Romanela Marcellino ${ }^{\mathrm{d}}$, Eunice Víquez-Ruiz ${ }^{\mathrm{b}}$, Carlos A. Robles ${ }^{\mathrm{d}}$, Caterina Guzmán-Verri ${ }^{\mathrm{b}}$ \\ ${ }^{a}$ Centro de Referencia en Levaduras y Tecnología Cervecera (CRELTEC), Instituto Andino Patagónico de Tecnologías Biológicas y Geoambientales (IPATEC), Consejo \\ Nacional de Investigaciones Científicas y Técnicas, Universidad Nacional del Comahue, San Carlos de Bariloche, Río Negro, Argentina \\ ${ }^{\mathrm{b}}$ Programa de Investigación en Enfermedades Tropicales, Escuela de Medicina Veterinaria, Universidad Nacional, Heredia, Costa Rica \\ ${ }^{\mathrm{c}}$ Parasites and Microbes from Pathogen Genomics, Wellcome Trust Sanger Institute, Hinxton, United Kingdom \\ ${ }^{\mathrm{d}}$ Grupo de Salud Animal, Estación Experimental Agropecuaria Bariloche, Instituto Nacional de Tecnología Agropecuaria, San Carlos de Bariloche, Río Negro, Argentina
}

\section{A R T I C L E I N F O}

\section{Keywords:}

Brucella ovis

Genotyping

MLVA

\begin{abstract}
A B S T R A C T
Brucellosis in rams is caused by Brucella ovis or Brucella melitensis and it is considered one of the most important infectious diseases of males in sheep-raising countries. Molecular characterization of Brucella spp. achieved by multi-locus variable number of tandem repeats analysis (MLVA) is a powerful tool to genotype Brucella spp. However, data regarding $B$. ovis genotyping is scarce. Thus, the aim of this study was to characterize the molecular diversity of $B$. ovis field-strains in Argentina. A total of 115 isolates of $B$. ovis from Argentina and Uruguay were genotyped using MLVA-16 and analyzed altogether with 14 publicly available B. ovis genotypes from Brazil. The Discriminatory Power (D) was 0.996 for MLVA-16 and 0.0998 for MLVA-8 and MLVA-11. Analysis of MLVA-16 revealed 100 different genotypes, all of them novel, including 90 unique ones. There was no correlation between geographical distribution and genotype and results showed a higher diversity within provinces than between provinces. Clustering analysis of the strains from Argentina, Uruguay and Brazil revealed that the 129 isolates were grouped into two clades. Whole Genome Sequencing analysis of the 19 B. ovis genomes available in public databases, and including some of the Argentinian strains used in this study, revealed clustering of the Argentinian isolates and closer relationship with B. ovis from New Zealand and Australia. This work adds new data to the poorly understood distribution map of genotypes regionally and worldwide for $B$. ovis and it constitutes the largest study of $B$. ovis molecular genotyping until now.
\end{abstract}

\section{Introduction}

Brucellosis in rams can be caused by both Brucella ovis and Brucella melitensis and it is considered one of the most important infectious diseases of males in sheep-raising countries (Blasco, 1990).

In Argentina, ovine brucellosis is almost exclusively caused by $B$. ovis, with epididymitis and male infertility being the main clinical signs (Robles et al., 1998). Patagonia, a vast area of 782,112 $\mathrm{km}^{2}$, includes five provinces with two thirds of the 12 million sheep farmed in Argentina, constituting the most important sheep breeding region in this country (Cardellino and Mueller, 2002). B. ovis infection was recorded for the first time in Argentina in 1962 by Szyfres \& Chappel who isolate B. ovis from the semen of a ram with epididymitis. In Patagonia, B. ovis was first isolated in 1963 in rams from Tierra del Fuego Island (Cedro et al., 1963). In 1993, Robles et al., carried out the first serological survey on B. ovis in Patagonia. This survey showed that $28.6 \%$ (12) of over 42 sheep farms belonging to eight different departments of Chubut province, resulted positive to $B$. ovis infection. Of the 345 animals sampled, 15 resulted positive given a general animal prevalence of 4.3 $\%$. The following year, a similar study carried out in 18 sheep farms from Santa Cruz province, found $27.7 \%$ of farms infected and the animal prevalence was $2.15 \%$ in 1,301 ram blood samples (Iglesias et al., 1994). These two studies early demonstrated that infection by B. ovis was spread in the two most important sheep raising provinces of Argentina.

In America, B. ovis infection has been diagnosed with certainty in the USA, Mexico, Bolivia, Peru, Brazil, Chile, Argentina and Uruguay. However, is suspected in other countries, such as Canada (Bulgin, 1990; Costa et al., 2012; Mederos, 1995; Robles et al., 1998; Rojas et al., 1990).

Molecular epidemiology of Brucella spp. can be challenging due to the low genetic variation in its genome (Tsolis et al., 2009). In spite of this, its molecular characterization has been achieved by multilocus variable number of tandem repeats analysis (MLVA), a powerful tool to

\footnotetext{
* Corresponding author at: Quintral 1250, CP8400, Bariloche, Río Negro, Argentina.

E-mail address: alvarez.lucia@comahue-conicet.gob.ar (L.P. Alvarez).
} 
determine relationships among Brucella spp. isolates from different animal species, as well as for epidemiological trace-back studies (Al Dahouk et al., 2007; Le Fleche et al., 2006; Vergnaud et al., 2018). Data regarding $B$. ovis genotyping, using MLVA or other techniques is still very scarce. Up to date, only $19 \mathrm{~B}$. ovis genomes are publicly available from limited geographical regions. Therefore, the aim of this study was to characterize the molecular diversity of B. ovis field-strains in Argentina and relate these findings to those obtained worldwide.

\section{Methods}

\subsection{Sample collection and isolation of B. ovis strains}

A total of 115 strains of $B$. ovis from the Brucellosis Laboratory (Red Lab № 185) at the Animal Health Group, INTA Bariloche (Argentina) were used in this study. Three of them were obtained from Uruguay (S1 Table). Samples were submitted to our laboratory by veterinary practitioners from sheep farms that were under brucellosis control programs. The 112 Argentinian strains were obtained between 1993 and 2014 from semen samples or seminal vesicles collected from naturally diseased rams from sheep farms of four different Patagonian provinces as follows: Chubut (62, $55.35 \%$ ), Rio Negro (24, $21.43 \%)$, Tierra del Fuego $(24,21.43 \%)$ and Neuquen (2, $1.78 \%$ ) (Table 1). Original semen samples or seminal vesicles homogenates were plated on Columbia agar (Britania) supplemented with $7 \%$ of sheep blood and on Modified Thayer Martin medium prepared at our laboratory (GC Medium base $38 \mathrm{~g} / \mathrm{l}$ (Biolife), Hemoglobine $10 \mathrm{~g} / \mathrm{l}$ (Difco), Vancomycin $3 \mathrm{mg} / \mathrm{l}$ (Sigma), Colistin $7.5 \mathrm{mg} / \mathrm{l}$ (Sigma), Nystatin 100.000 U.I./1 (Sigma), Nitrofurantoin $10 \mathrm{mg} / \mathrm{l}$ (Sigma)).

\subsection{DNA isolation, Bruce-Ladder, high resolution melting RT-PCR and Sanger sequencing}

Total genomic DNA was extracted from pure isolates using the Accuprep Genomic DNA Extraction Kit (Bioneer) according to the manufacturer's instructions and stored at $-20{ }^{\circ} \mathrm{C}$ until use. DNA was quantified using a Qubit 3 Fluorometer (Thermo Scientific) according to manufacturer's instructions.

Bruce-ladder was carried out as previously described (López-Goñi et al., 2008). High Resolution Melting RT-PCR using primers to amplify glk gene (163 bp) to identify $B$. ovis was performed according to Winchell et al. (2010). DNA sequencing of amplicons from selected samples was performed using the Big Dye terminator kit 3.1 (Life Technologies) according to manufacturer's instructions.

\subsection{MLVA-16 genotyping}

Briefly, MLVA-16 was performed as described previously (Le Flèche et al., 2006; Al Dahouk et al., 2007). The 16 primer pairs were divided into three groups: Panel 1 (eight loci including bruce06, bruce08, bruce11, bruce12, bruce42, bruce43, bruce45 and bruce55), panel 2A (three loci including bruce18, bruce19 and bruce21) and panel 2B (five loci including bruce04, bruce07, bruce09, bruce16 and bruce30). MLVA-8 includes panel 1, MLVA-11 includes panel 1 and panel $2 \mathrm{~A}$ and MLVA-16 includes panel 1, panel 2A and panel 2B. PCR amplifications were performed in $15 \mu \mathrm{L}$ reaction volumes. The PCR conditions were as follows: initial denaturation at $94{ }^{\circ} \mathrm{C}$ for $3 \mathrm{~min}$ and then 30 cycles of 94 ${ }^{\circ} \mathrm{C}$ for $30 \mathrm{~s}, 60{ }^{\circ} \mathrm{C}$ for $30 \mathrm{~s}$ and $72{ }^{\circ} \mathrm{C}$ for $50 \mathrm{~s}$, with a final extension of 72 ${ }^{\circ} \mathrm{C}$ for $3 \mathrm{~min}$. PCR products for the 16 loci were resolved by capillary electrophoresis on an QIAxcel Advance ${ }^{\circledast}$ electrophoresis system (Qiagen ${ }^{\circledR}$ ).

The resulting genotypes were compared using the web-based Brucella 2016 MLVA database (http://mLva.u-psud.fr/) together with 14 additional isolates from Brazil (Dorneles, 2014) Also and strain REO198 genotype from the USA. All MLVA profiles obtained in this study are available at http://microbesgenotyping.i2bc.paris-saclay.fr/ and in S1 Table.

Total number of alleles, genetic diversity and Shannon's information index for each population, and the number of private alleles per population and region were calculated using GenAlEx 6.5 (Peakall and Smouse, 2012). The genetic differentiation between populations was determined using phiPT, a measure that allows intra-individual variation to be suppressed and is therefore ideal for comparing codominant and binary data, with 10,000 permutations. Analysis of molecular variance (AMOVA) among and within populations and geographical regions was performed using GenAlEx. Dendograms were constructed using the MLVA Microbes Genotyping platform and they were visualized using FigTree v1.4.3 software. Dendograms and geographical distribution were visualized as a microreact project, available at https://microreact.org/project/q30-j0p_P (Argimón et al., 2016). The Discriminatory Power (D) for MLVA-16, MLVA-11 and MLVA-8 was calculated using the calculator of the website http://insilico.ehu.es/ mini_tools/discriminatory_power/index.php.

\subsection{Phylogenetic reconstruction and WGS based analysis}

A total of $19 \mathrm{~B}$. ovis genomes previously available in public databases, were used in this analysis (Table 1); 12 of them are from Argentinian samples. The detailed information and metadata of the genomes is presented in S1 Table. Bwa and SMALT v.0.5.8 T were used to construct a multiple sequence alignment for phylogenetic reconstruction of the $19 \mathrm{~B}$. ovis reads altogether with reads of seven additional genomes from different Brucella species and two Ochrobactrum species (Ochrobactrum anthropi and Ochrobactrum intermedium) in order to add phylogenetic context. Brucella suis st. 1330 was used as reference in the alignment, which showed $95 \%$ average coverage among Brucellae. Single Nucleotide Polymorphisms (SNPs) were called using Samtools (Li et al., 2009), and 3,315,278 variable sites were extracted using SNP sites (Page et al., 2016). When Ochrobactrum was excluded, a total of 24,322 SNPs were revealed. The whole alignment was used for maximum likelihood phylogenetic reconstruction with RAxML v8 (Stamatakis et al., 2014). Ochrobactrum was used as outgroup for the phylogenetic tree visualization with Figtree v1.4.3 (http://tree.bio.ed. ac.uk/software/figtree/); the phylogeographic relationship and metadata analysis were facilitated by Microreact (Argimón et al., 2016) (https://microreact.org/project/bru-LhIFZ).

\section{Results and discussion}

Ovine brucellosis in Argentina is an important infectious disease that produces loss of productivity in sheep raising farms. In spite of this, very little is known about the genetic variability of circulating B.ovis

Table 1

Sumary of samples metadata analysed in this study. Detailed information in S1 Table and https://microreact.org/project/q30-j0p_P.

\begin{tabular}{|c|c|c|c|c|}
\hline Geographical Region & Number of Isolates & Number of Tested Farms & Years of Testing & WGS Accession Number of Available Genomes \\
\hline Chubut & 62 & 2 & 2008,2009 & SRS401659; SRS401660; SRS401658 \\
\hline Río Negro & 24 & 3 & 2001, 2006, 2014 & SRS401653; SRS401652; SRS401657; SRS401655 \\
\hline Tierra del Fuego & 24 & 1 & 2010 & SRS401661; SRS401662 \\
\hline Neuquen & 2 & 2 & 1993, 2002 & SRS401654; SRS401662 \\
\hline Uruguay & 3 & ND & 2015 & None \\
\hline
\end{tabular}




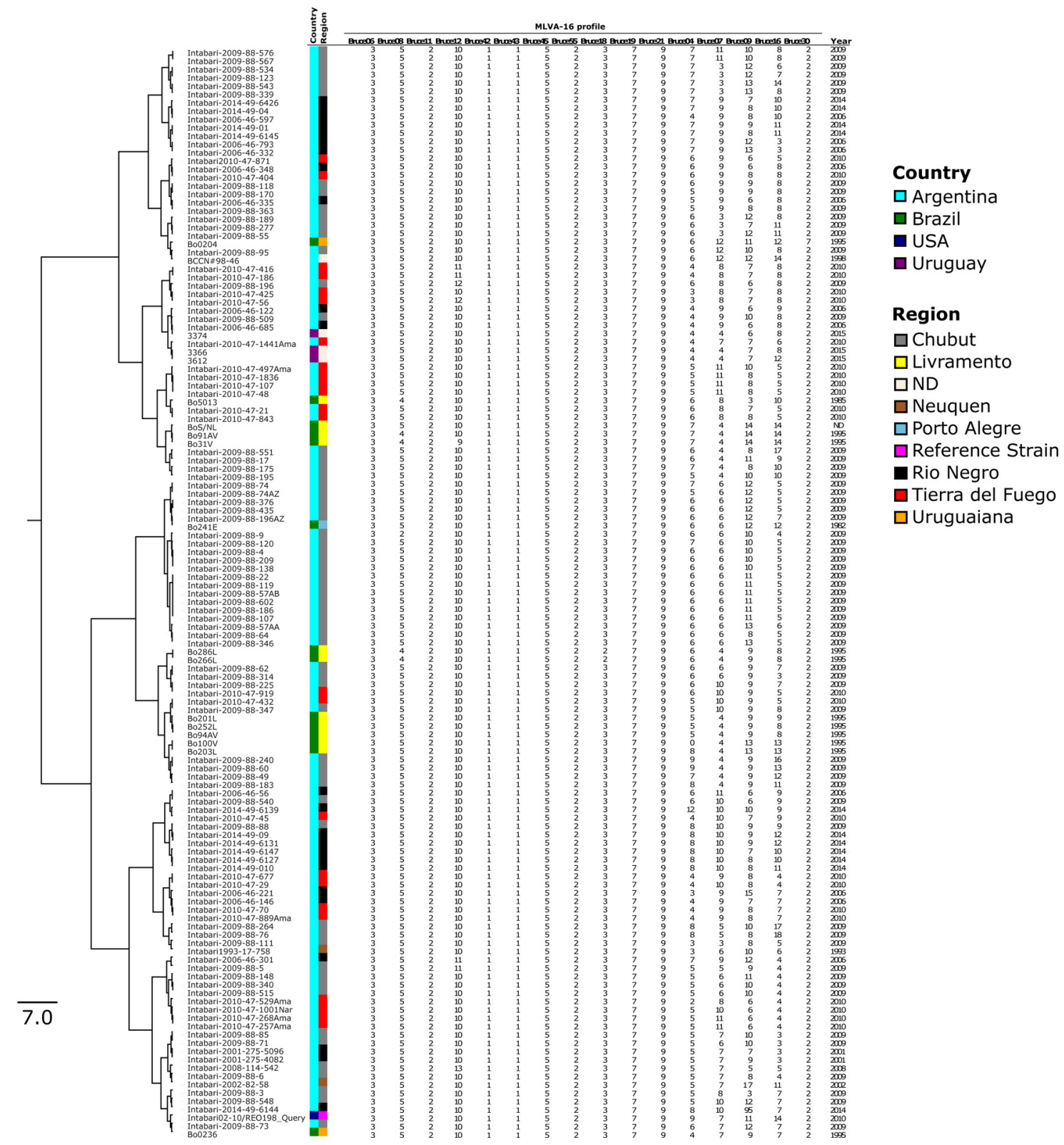

Fig. 1. MLVA-16 clustering analysis of $\boldsymbol{B}$. ovis isolates. Dendogram showing MLVA-16 of $131 \mathrm{~B}$. ovis isolates. The following data are given from left to right: country, region, MLVA-16 profile, and isolation year. Information on the origin of the isolates is color labeled. For additional details and increased resolution see https://microreact.org/project/q30-j0p_P.

strains and its impact in virulence. Cedro et al. (1963) reported the disease and isolated B. ovis from Corriedale rams in Tierra del Fuego province for the first time in Patagonia. A serological study, carried out more recently during 1995-2010 in the five Patagonian provinces, including 181,495 serum samples from rams belonging to 758 farms, revealed that $66.2 \%$ of sheep farms have at least one infected ram, and an average B.ovis prevalence of $5.8 \%$ ranging from $3.2 \%$ for Chubut province to $8.2 \%$ for Santa Cruz province (Robles, 2012).

In this work, a total of 115 isolates obtained from non random sampling were identified as B. ovis by biochemical tests (Alton, 1990) and Bruce-ladder ( $\mathrm{S} 1$ Table). The Bruce-ladder showed the expected pattern for $B$. ovis for every isolate, validating this technique for use in identifying field isolates of $B$. ovis. On the other hand, HRM RT-PCR analysis for $B$. ovis identification showed high variation and therefore was inconclusive. This variation was not related to amplicon differences, since both in silico PCR and Sanger sequencing was performed using available $B$. ovis genome sequences with no differences at the nucleotide level. Our results suggest that this approach needs careful standardization and validation before it can be used as a complementary laboratory technique for $B$. ovis identification. Until its economic cost is lowered, alternative techniques are more feasible for diagnostic laboratories.

The D analysis of MLVA confirmed the MLVA-16 high discriminatory power. The diversity index (h) for panel 1 (MLVA-8) ranged from 0 to 0.071 , for panel 2A (MLVA-11) ranged from 0 to 0.036 and for panel 2B (MLVA-16) ranged from 0.024 to 0.650 . The most diverse loci were Bruce04 (h: 0.472), Bruce07 (h: 0.428), Bruce09 (h: 0.650) and Bruce16 (h: 0.553), this agrees with Garofolo et al. (2013). The D was 0.996 for MLVA-16 and 0.0998 for MLVA-8 and MLVA-11. This confirms the need to include panel $2 \mathrm{~B}$ in $B$. ovis genotyping to detect differences among isolates.

Analysis of MLVA-16 revealed 100 different genotypes, which were all novel, with 90 unique genotypes. Interestingly, among $62 \mathrm{~B}$. ovis isolates from the same farm, only six strains had identical patterns 

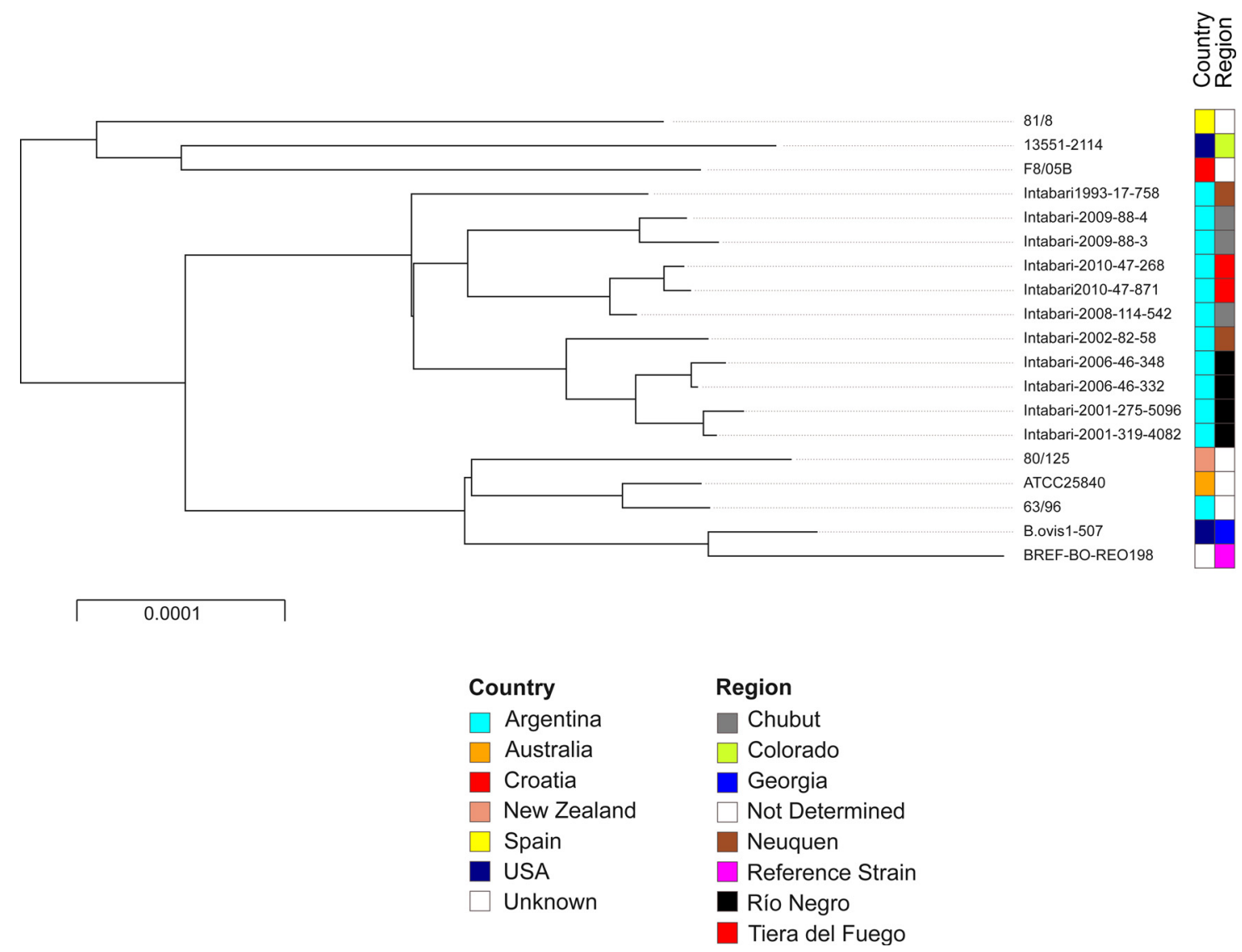

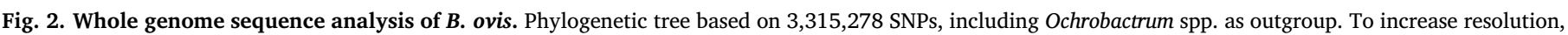

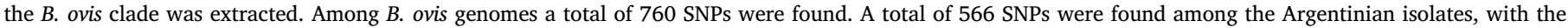
exception of strain 63/96. For increased resolution and metadata see https://microreact.org/project/bru-LhIFZ.

\section{(Fig. 1).}

Accordingly, Dorneles et al. (2014) found that 13 of the 14 B. ovis isolates analyzed in their study, had different and novel genotypes. Similarly, Al Dahouk et al. (2007) found 101 different genotypes in 144 B. melitensis isolated from humans, whereas Garofolo et al. (2013) found 90 different genotypes in 206 isolates of B. abortus and B. melitensis from Italy. These findings, as well as our results, confirm that Brucella genus is more variable than previously considered, and that more genotypes could be revealed as more studies with higher number of isolates are performed.

There was no correlation between geographical distribution and genotype of the samples $\left(R^{2}=0.013\right)$. This was predictable since the sampling was not designed to evaluate this possible correlation. Moreover, there is a sample bias, since samples from Chubut are overrepresented when compared to other regions.

Results showed a higher diversity within provinces than among provinces (PhiPT, $87 \%$ vs $13 \%, \mathrm{p}=0.01$ ). There was also a high diversity among $B$. ovis isolates, even among isolates of the same herd. This might be due to the introduction of infected rams without any previous serological analysis or semen culture from other sheep flocks or sheep studs. This is commonly done by farmers with the aim to improve some desired genetic characteristics in their own flock and also to avoid consanguinity.

The clustering analysis of the strains from Argentina (112 isolates), Uruguay ( 3 isolates) and Brazil (14 isolates) revealed that all isolates were grouped into two clades (Fig. 1).

Twelve of the isolates analyzed in this study had WGS available in public databases. Up to date, there are only 19 WGS in total available, showing that there is much to know on the genetics of this pathogen. A SNPs based phylogenetic tree was constructed using other Brucella species as context and Ochrobactum anthropi as outgroup (Fig. 2).

Phylogeographic analysis revealed clustering of the Argentinian isolates and closer relationship with $B$. ovis from New Zealand and Australia, particularly with the Argentinian isolate 63/96. This could be due to the fact that most of the Merino in Argentina came from those two countries. There was no correlation between the phylogenetic relationships found among the Argentinian isolates and the clusters found by MLVA-16. Also, no correlation with the Argentinian geographical region nor isolation date was observed. This difference may be explained by the higher resolution power provided by WGS and homoplasy described for other Brucella, such as B. abortus VNTR markers (Suárez-Esquivel et al., 2020). Lack of a higher number of WGS and MLVA $B$. ovis published phenotypes precludes further conclusions.

In conclusion, this study allowed us to take the first steps towards the characterization of the molecular diversity of $B$. ovis field-strains in Argentina and relate these findings to those obtained worldwide.

To our knowledge, this work constitutes the largest study of $B$. ovis molecular genotyping until now adding new data to the scarce available information available at the regional and worldwide level.

\section{Funding}

This work was supported by grants from Agencia Nacional de Promoción de la Investigación, el Desarrollo Tecnológico y la Innovación (ANPCyT), Argentina (PICT2013-0366; PICT2016-0636); Instituto Nacional de Tecnología Agropecuaria (INTA), Argentina (PNSA 1115052); Ministerio de Modernización, Argentina (Fellowship and grant BEC.AR); Fondos Estatales de la Educación Superior, Consejo Nacional de Rectores (FEES-CONARE), Costa Rica (UNA SIA project 0260-14). 


\section{Appendix A. Supplementary data}

Supplementary material related to this article can be found, in the online version, at doi:https://doi.org/10.1016/j.vetmic.2020.108703.

\section{References}

Al Dahouk, S., Flèche, P.L., Nöckler, K., Jacques, I., Grayon, M., Scholz, H.C., et al., 2007. Evaluation of Brucella MLVA typing for human brucellosis. J. Microbiol. Methods 69, 137-145.

Alton, G., 1990. Brucella melitensis. In: Nielsen, Duncan (Eds.), Animal Brucellosis. CRC Press, Florida, pp. 383-409.

Argimón, S., Abudahab, K., Goater, R., Fedosejev, A., Bhai, J., Glasner, C., et al., 2016. Microreact: visualizing and sharing data for genomic epidemiology and phylogeography. M. Gen. 2 (11), 1-11.

Blasco, J.M., 1990. Brucella ovis. In: Nielsen, K., Duncan, R. (Eds.), Animal Brucellosis. CRC Press, Florida, pp. 453.

Bulgin, M.S., 1990. Epididymitis in rams and lambs. Vet. Clin. North Am. Food Anim. Pract. 6, 683-690.

Cardellino, R., Mueller, J., 2002. Merino production in South America: from the Andes to the Atlantic Ocean. In: Cape Wools 9th World Merino Conference. Stellenbosch, South Africa.

Cedro, V.C., Cisale, H.O., de Benedetti, L., 1963. Brucelosis genital ovina. Epididimitis del carnero. Revista de Investigaciones Ganaderas 16, 12-18.

Costa, E.A., Sant'Anna, F.M., Carvalho, C.J.S., Moustacas, V.S., Silva, S.M.M.S., Paixao T.A., et al., 2012. Diagnosis of Brucella ovis infection by serology and PCR in urine samples from naturally infected rams in the State of Piauí. Arquivo brasileiro de medicina veterinária e zootecnia 64, 751-754.

Dorneles, E.M.S., Freire, G.N., Dasso, M.G., Poester, F.P., Lage, A.P., 2014. Genetic diversity of Brucella ovis isolates from Rio Grande do Sul, Brazil, by MLVA16. BMC Res. Notes 7, 447.

Garofolo, G., Di Giannatale, E., De Massis, F., Zilli, K., Ancora, M., Cammà, C., et al., 2013. Investigating genetic diversity of Brucella abortus and Brucella melitensis in Italy with MLVA-16. Infect. Genet. Evol. 19, 59-70.

Iglesias, R., Tapia, H., Batarev, S., 1994. Relevamiento de Brucelosis ovina en carneros de la provincia de Santa Cruz. Rev. Arg. Prod. Anim. 14 (1), 137.

Le Flèche, P., Jacques, I., Grayon, M., Al Dahouk, S., Bouchon, P., Denoeud, F., et al.,
2006. Evaluation and selection of tandem repeat loci for a Brucella MLVA typing assay. BMC Microbiol. 6, 9.

Li, H., Handsaker, B., Wysoker, A., Fennell, T., Ruan, J., Homer, N., et al., 2009. The sequence alignment/map format and SAMtools. Bioinformatics 25 (16), 2078-2079.

López-Goñi, I., García-Yoldi, D., Marín, C.M., de Miguel, M.J., Muñoz, P.M., Blasco, J.M., et al., 2008. Evaluation of a multiplex PCR assay (Bruce-ladder) for molecular typing of all Brucella species, including the vaccine strains. J. of Clin. Microb. 46, 3484-3487.

Mederos, A., 1995. Brucelosis ovina. Estudio epidemiologico y económico de Brucella ovis en el departamento de Tacuarembó, Uruguay. Serie técnica № 69, Ed. INIA Uruguay.

Page, A.J., Taylor, B., Delaney, A.J., Soares, J., Seemann, T., Keane, J.A., et al., 2016. SNP-sites: rapid efficient extraction of SNPs from multi-FASTA alignments. Microb Genomics 2 (4), e000056.

Peakall, R., Smouse, P.E., 2012. GenAlEx 6.5: genetic analysis in Excel. Population genetic software for teaching and research-an update. Bioinformatics 28, 2537-2539.

Robles, C.A., La Torraca, A., Sancholuz, M., Uzal, F.A., Evans, E., 1993. Brucelosis ovina en majadas Merino de la provincia de Chubut, Argentina. Vet. Arg. 10, 458-461.

Robles, C.A., Uzal, F.A., Olaechea, F.V., Low, C., 1998. Epidemiological observations in a Corriedale flock affected by Brucella ovis. Vet. Res. Commun. 22, 435-443.

Robles, C.A., Martínez, A., Chodilef, M., 2012. Brucelosis ovina en Patagonia: Análisis de 15 años de diagnóstico en el Laboratorio de Brucelosis del INTA Bariloche. XIX Reunión Científico-Técnica AAVLD. Buenos Aires, Argentina. Abstract. .

Rojas, X., Alonso, O., Rosenfeld, C., Uribe, C., Fernandez, V., Tadich, N., 1990. Brucelosis ovina. Situación actual en explotaciones de una comuna del sur de Chile. Arch. Med. Vet. XXII (1), 55-63.

Stamatakis, A., 2014. RAxML version 8: a tool for phylogenetic analysis and post-analysis of large phylogenies. Bioinformatics 30 (9), 1312-1313.

Szyfres, B., Chappel, R., 1962. Comprobación bacteriológica de la epididimitis infecciosa ovina en la República Argentina. Rev. Fac. Cien. Vet. de La Plata. 3, 405-409.

Tsolis, R.M., Seshadri, R., Santos, R.L., Sangari, F.J., Lobo, J.M., de Jong, M.F., et al., 2009. Genome degradation in Brucella ovis corresponds with narrowing of its host range and tissue tropism. PLoS One 4, e5519.

Vergnaud, G., Hauck, Y., Christiany, D., Daoud, B., Pourcel, C., Jacques, I., et al., 2018 Genotypic expansion within the population structure of classical Brucella species revealed by MLVA16 typing of 1404 Brucella isolates from different animal and geographic origins, 1974-2006. Front. Microbiol. 9, 1545.

Winchell, J.M., Wolff, B.J., Tiller, R., Bowen, M.D., Hoffmaster, A.R., 2010. Rapid identification and discrimination of Brucella isolates by use of real-time PCR and highresolution melt analysis. J. Clin. Microbiol. 48 (3), 697-702. 